The bulk of the work in connection with this investigation was carried out in the various departments of the hospital with the help and co-operation of the members of my staff. Dr. K. Koman Nayar (Assistant Superintendent), besides giving much other valuable assistance, took over the corneal microscope observations during my absences. Messrs. Venkatarangam Naidu, Narayanaswami Pillai, Narayanaswami Naidu, Narayana Iyer, and the late Dr. V. G. Muthayya, observed and made appropriate notes on the cases as they came under their departmental supervision. Mr. Narayanaswami Pillai, however, undertook the most laborious share in this combined effort, inasmuch as he was responsible for maintaining records of the individual cases, including the notes on biomicroscopical findings, selection of cases for experimental work, and all our hospital laboratory routine and animal work. Lt.-Col. H. H. King, I.M.S., Director of the King Institute of Preventive Medicine, Guindy, kindly gave his help and advice. He allowed $\mathrm{Mr}$. Theodore of his staff to visit the hospital frequently and co-operate with us in connection with the laboratory investigations. In this way we were enabled to keep in touch with the King Institute, which is situated seven miles away. Col. King supplied some of the rabbits, all of the monkeys and also the culture media and apparatus in connection with the filtration experiments. Mr. Theodore carried out a large portion of the animal experiments in groups $3,4,5$ and 12 and attended the hospital on numbers of occasions with all the necessary materials and apparatus to help in cultural and filtration work. Dr. Pandit, Assistant Director of the King Institute, Guindy, and Mr. Hawley of the Institute staff also lent their aid. To all these gentlemen my grateful acknowledgements are due.

\title{
TWO CASES OF SYMPATHETIC OPHTHALMITIS
}

BY

\section{J. WOOD \\ CAPE TOWN}

WITHIN the last year I have had two cases of sympathetic disease which, taken with the case described by me in this journal in May, 1927 , form an interesting trio.

The 1927 case (R. W.), one of gross disease of the choroid and iris in the exciting eye, followed by a serious infection of the sympathising eye, was unusual in the complete recovery which the sympathising eye made, so that to-day it possesses $6 / 4$ vision with scarcely a trace to tell the tale of what it had gone through. 
My third case is even more unusual as the sympathetic disease occurred after a successful operation for cataract where there were no symptoms to warn one of danger, and where the patient got, and still has, standard vision in the exciting eye.

The second case of the trio was a coloured boy (E. B.), who was wounded by a piece of wire in a fight. He had a wound of the upper corneal margin with prolapse of the iris. The prolapse was cut off next day, and a small conjunctival flap drawn over the wound. No redness or pain followed, but after two weeks the iris had changed its colour, was pushed forwards, and the tension had gone down. There were no deposits on the cornea. The eye was excised three weeks after the injury, and the boy left.

He was brought back in two weeks with failure of vision in the remaining eye. There was little redness, but definite deposits on the back of the cornea, and some adhesions of the iris. From that time there elapsed nearly a year, during which he had a long course of neo-salvarsan, sodium salicylate, mercury, and recently hexamine. None seemed to make any difference. There is still much " K.P.", little redness, but almost complete adhesion of the iris to the lens, and much deposit on the lens capsule. While one could still see into his eye there was congestion of the retinal vessels and loss of outline of the optic nerve. Microscopic examination of the exciting eye was rather surprising, as the dominant feature was a leucocytic extravasation, with few collections of lymphocytes, and very few plasma cells.

A few points may be mentioned by way of contrast to the next case.

Except at the wound the cornea was normal, but on Descemet's membrane there were clumps of polymorphonuclear leucocytes. The angle of the anterior chamber was full of them, as was the coagulum in the Chamber. (Fig. 1.) They were in large numbers in the iris, but it retained its proper tissue elements, and bleached sections (Fig. 2) showed that the uveal pigment cells, though irregular in size and arrangement, were present practically all along the back of the iris. At the pupillary region there was a definite lymphocyte collection. The frequency of these collections has probably a relation to the vicinity of the circulus minor. They are seen in many cases of continued iritis. The ciliary body on the side of the wound showed the ordinary changes seen in traumatic cyclitis, plus a rather large lymphocyte collection just below the surface, elsewhere the changes resembled those in the iris.

The retina had suffered more than one would have expected, the damage starting apparently from the inner surface. (Fig. 3.) The nerve fibre and ganglion cell layers were destroyed, and leucocytes were in large numbers as far back as the rods and cones. The optic nerve was normal. Except for the few collections of lympho- 
cytes the condition was not typical of sympathetic disease, but nevertheless it produced in the other eye a condition which was quite typical.

The third case of the trio (Mrs. M.), came to me in. December, 1927 , with commencing cataract. She was a woman aged 53 years, and had been injured in the left eye when a girl. She was treated by Sir George Berry, and had all her life a small cystoid cicatrix with an updrawn pupil. It had never given any trouble, and, till her sight failed as a result of cataract, she had never been incommoded by the little damage. I put her off for six months, but by that time she saw too ill for her household duties, and as the left lens was more opaque, I removed it on June 14, 1928. The operation was normal. No iridectomy was needed; and she would have been discharged in two weeks had she not given herself a corneal abrasion. Examination of the eye on account of this revealed about half a dozen spots on the back of the cornea, which, however, were very transitory. On August 7 I did her a discission of the lens capsule, and she got $6 / 6$ vision which she still has. She left with no visible abnormality save the updrawn pupil, perhaps a little more eccentric than at first.

She returned on September 1 with iridocyclitis in her right eye, precipitates on her cornea, redness and dim vision. As sympathetic disease seemed unthinkable, a careful examination was made, but nothing was found save one doubtful tooth which was removed. She grew steadily worse, her pupil keeping small, the precipitates increasing, and the eye looking like a sympathetic case. Her left eye was absolutely free from any suggestion of inflammatory mischief. (Slit-lamp examination.)

She went away for a change and was absent for some months, but returned much worse, with severe pain, and no perception of light. I advised the removal of the eye, and she gladly agreed. It was removed on March 21, 1929. This was nearly nine months after the operation for cataract, and much longer therefore than would have been the case had one had to remove an exciting eye. Also as there had been no wound in the sympathising eye, one had to do with the effects of uncomplicated sympathetic disease. The eye on section showed the vitreous coagulated, and the retina in place. It was embedded in celloidin, cut, and stained in various ways. Heidenhain's iron-alum-haematoxylin gave the best results in the way of detail. The bacillary layer of the retina was only slightly abnormal, but every other portion of the eye was more or less damaged by infiltration or destruction, and the predominating feature was the presence everywhere of vast numbers of plasma cells. These stained better with Heidenhain's method than by any other tried, their chromatin marking in the nucleus being very striking, and unmistakable. Lymphocytes stained deep blue or 
black, while the nuclei of endothelial cells stained only a faint bluc. All three are therefore easily and certainly observed.

It was found that, except in the iris, plasma cells and lymphocytes were fairly sharply separated. Lymphocyte nodules, where they occurred, were bordered by plasma cells, not mixed with them. In the retina larger vessels had a coating of lymphocytes, while small ones had a layer of plasma cells round them. A mixture of the two kinds of cells such as was found in my 1927 case did not occur. Endothelial nuclei were found nearly everywhere, but not in collections, and giant cells were not found anywhere except in the cell exudate in front of the optic papilla, a situation where one would not have expected to find them.

Taking the tissues from before backwards, one found that the corneal epithelium was unaltered save for intrusive lymphocytes in small numbers which had penetrated Bowman's membrane. Beneath this, all round the corneal margin, was a zone of lymphocytes bordered by plasma cells, with increase of the corneal cells proper. This had been invisible during life, showing a greater transparency to have been present than is usually the case with corneal exudates. At the margin of the plasma cell exudate there were cells showing intermediate changes. Some nuclei showed multiple nucleoli, in others the chromatin was broken into masses, while others showed the characters of the plasma cell but in a nucleus still oval. A similar process could be seen in the cells of the tissue filling the anterior chamber, and also in the iris proper. Descemet's membrane appeared normal, and one could trace its endothelium nearly everywhere, but as the anterior chamber was full of new-formed tissue there was a doubt whether it was derived from the iris or possibly from the corneal endothelium. The former is, however, much the more probable. The cells in the anterior chamber were very definitely in layers (Figs. 4, 5, 6) and the nuclei, though mostly long ovals, all showed the plasma cell facies in their chromatin marking.

There was a definite separation line between these cells and the plasma cell collection which represented the iris. During life they were sufficiently transparent to give the impression that there was a shallow anterior chamber.

The iris has been changed into a mass of closely packed plasma cells, with some scattered lymphocytes and endothelial cells. (Fig. 4.)

The blood vessels have undergone hyaline degeneration (Figs. 7 and 8). No muscular coat is visible, and the adventitia is thickened, transparent, and devoid of the normal finely fibrillar structure. It gives the staining reactions characteristic of early hyaline change, taking a pink with eosin and a fairly bright red with van Giesen's stain. Hyaline degeneration is indicative of 


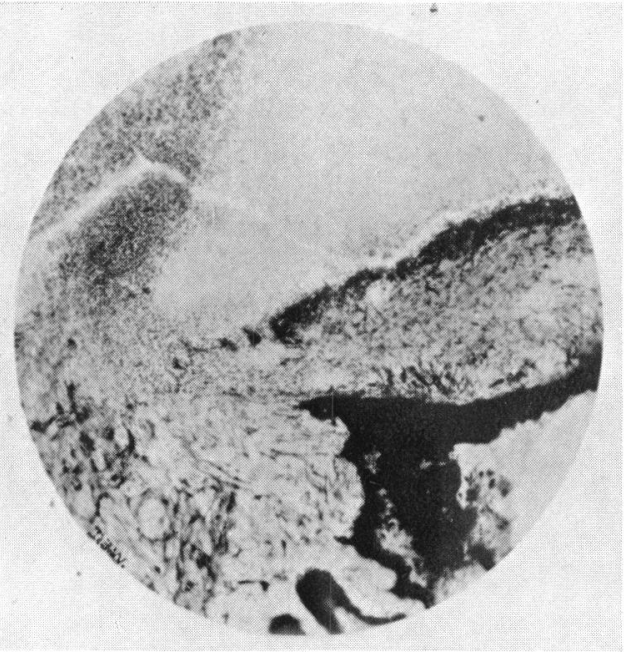

FIG. 1.

E.B. Angle of anterior chamber and iris, both full of leucocytes, which are also seen on surface of iris and back of cornea. Pigment layer not destroyed. $\times 70$

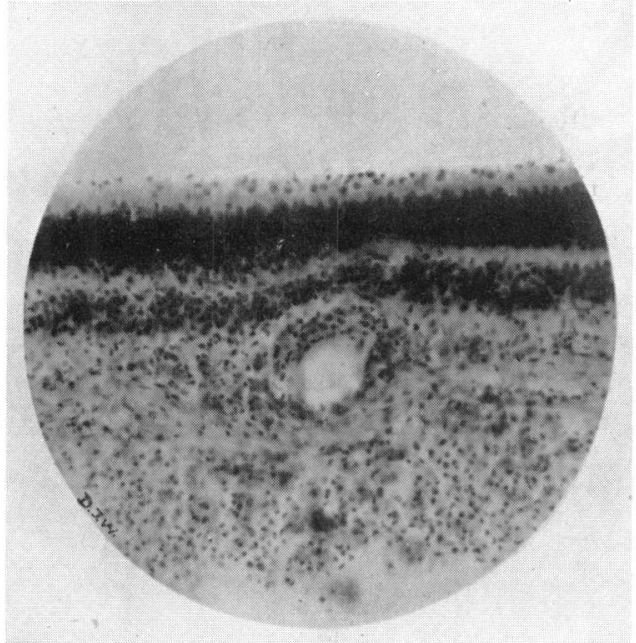

FIG. 3.

E.B. Retina invaded by leucocytes, nerve fibre and ganglion cells destroyed. $\times 140$

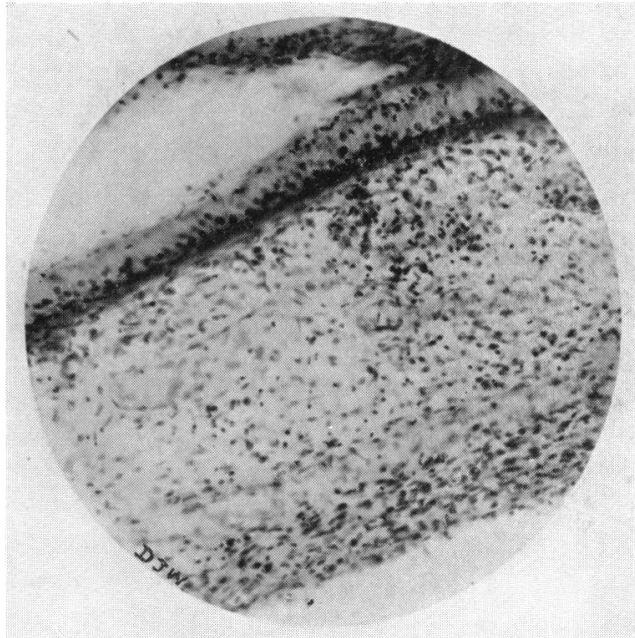

FIG. 2.

E.B. Iris bleached to show cells of pigment layers. Dilatator pupillae can be seen lying beneath them. $\times 140$

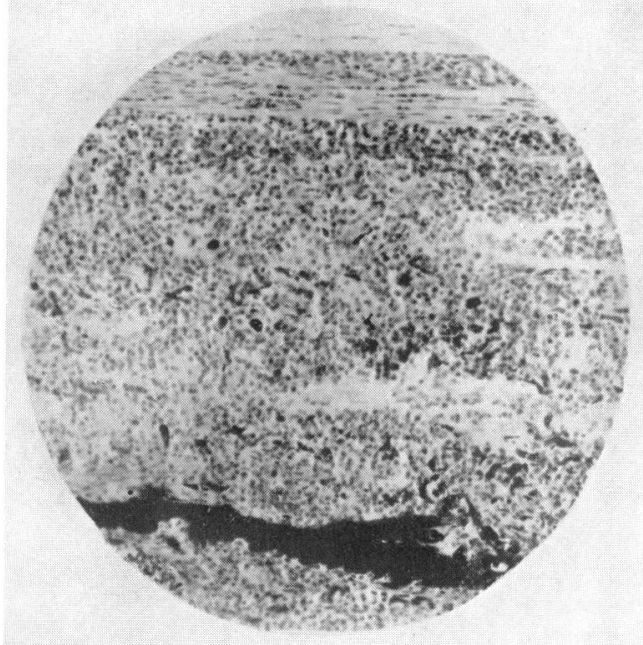

FIG. 4.

Mrs. M. Iris changed into mass of plasma cells. Filling anterior chamber are layers of cells whose nuclei show plasma cell marking Iris contains remains of extra-cellular pigment, and vessels formed by endothelium only. Behind the irregular line of pigment are more plasma cells, cells from the ciliary epithelium and broken down nuclei. $\times 140$ 


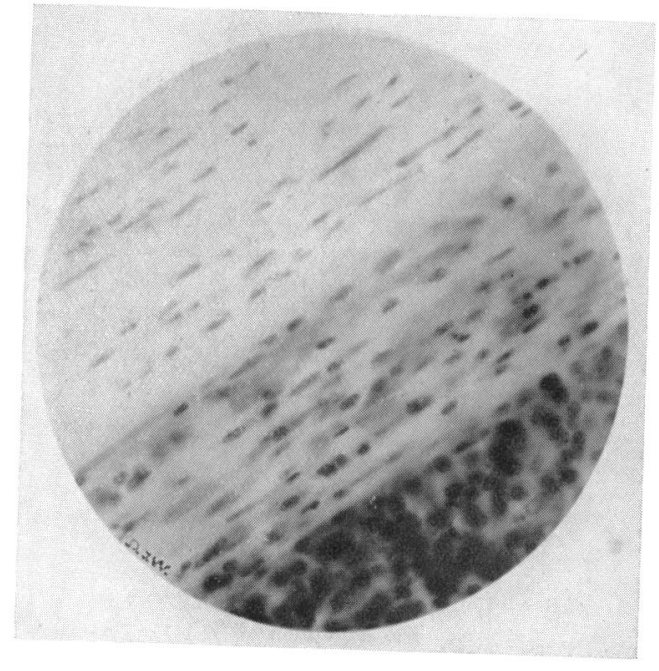

FIG. 5.

Mrs. M. Cells between cornea and iris. $\times 280$

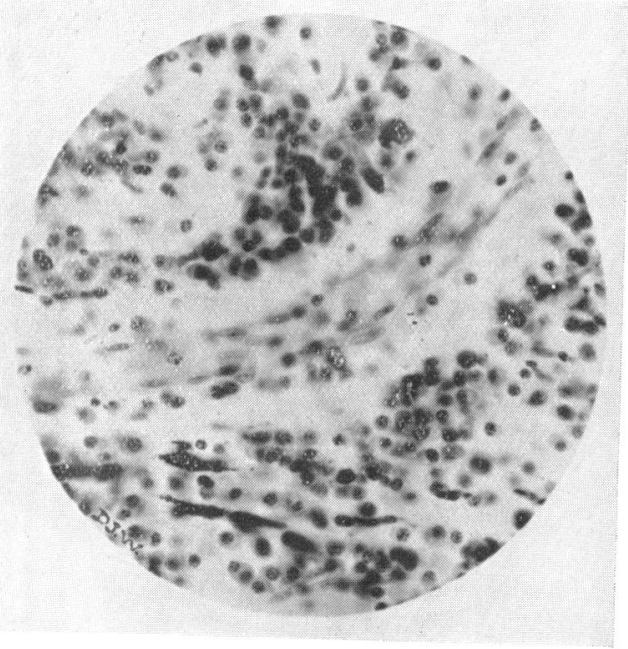

FIG. 7.

showing in the hyaline substance are in material round an endothelial tube. Most, if not all of the cells hyaline exudate. $\times 280$.
FIG. 6.

Mrs. M. The same under higher power to show the plasma cell marking. $\times 560$

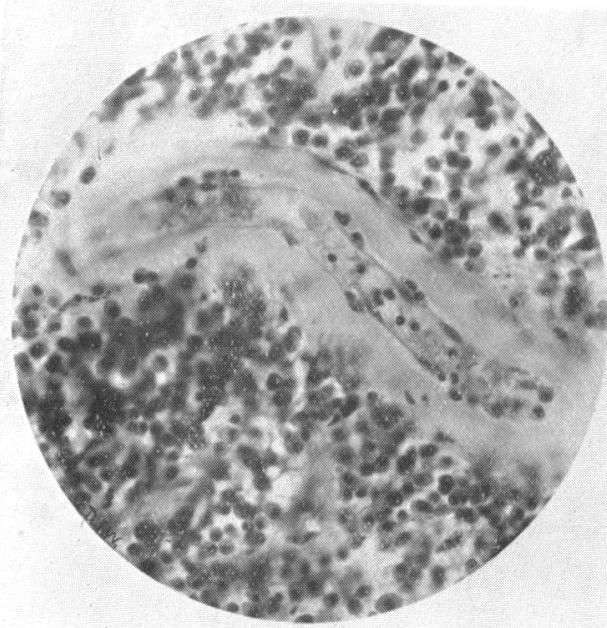

FIG. 8. 


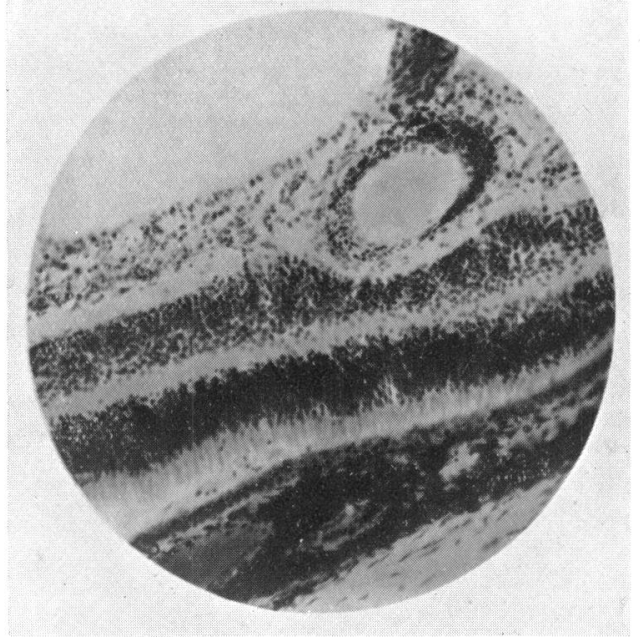

FIG. 9.

Mrs. M. Retina. Inner layers full of plasma cells A large vessel with its sheath of lymphocytes. $\times 140$

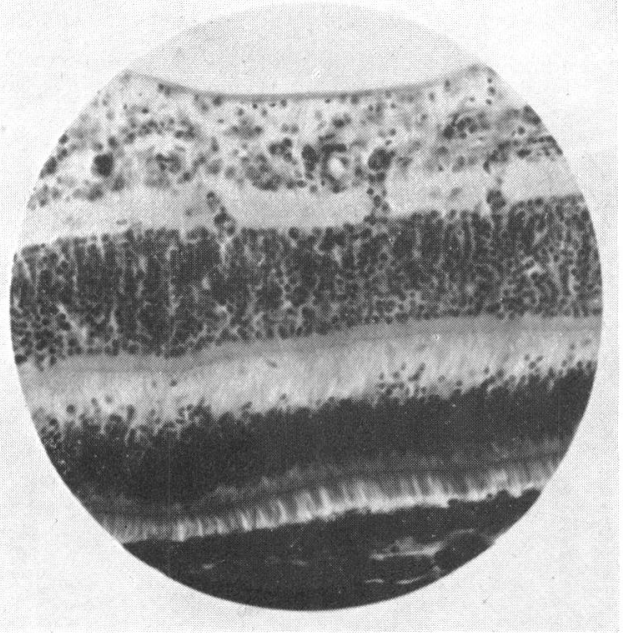

FIG. 11.

Mrs. M. Nerve fibre and ganglion cell layers showing plasma cells covering small vessels lying parallel to the surface and sending smaller branches into the bipolar cells.

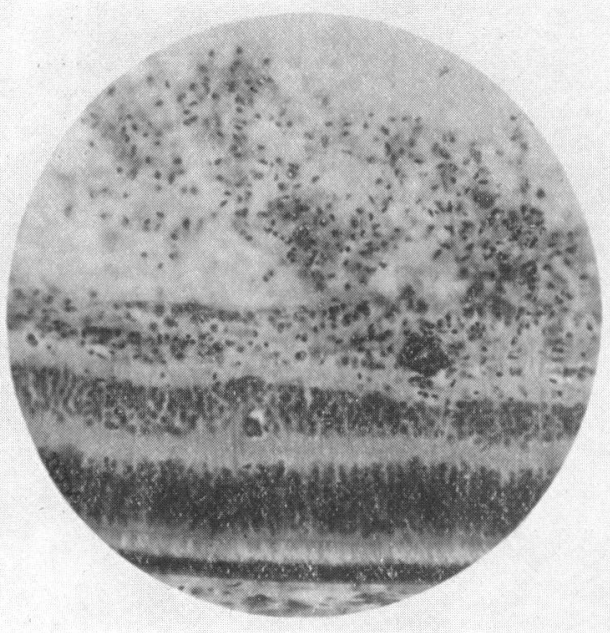

FIG. 10.

Mrs. M. Lymphocytes which have penetrated membrana limitans interna and entered vitreous. $\times 140$

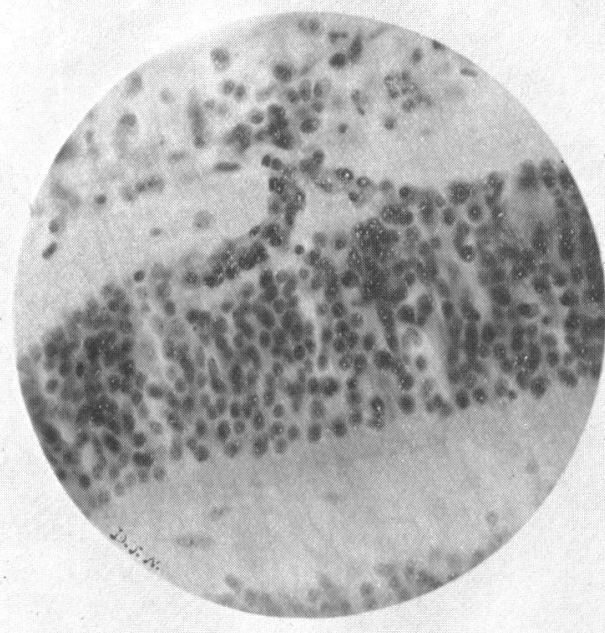

FIG. 12.

Mrs. M. Detail of same. $\times 480$ 
acute infective processes, and is not infrequently found in eyes excised for iridocyclitis. The endothelium appears unaltered. Some vessels contain blood, others are empty. Few, however, seem to be normal in the amount of blood present, and in a good many the blood cells are only ghosts, hardly staining with eosin.

The hyaline tubes are surrounded with endothelial or perithelial cells, and are sharply separated from the plasma cells round about. The hyaline matter is so transparent that only careful focusing shows that plasma cells are in front of or behind and not in the hyaline matter. In several sections one could see that endothelial cells near the blood vessels showed a plasma cell marking in their chromatin.

Everywhere one could see plasma cells which contained two nuclei, and with a cell body a third bigger than normal. In spite, however, of many hours spent in examining sections I found only one instance of mitosis in what seemed to be a plasma cell. The chromosomes were arranged at the two poles of an elliptical nucleus in an oval cell staining in the same way as surrounding plasma cells. Either the plasma cell is an end product, or it is very stable and the act of mitosis occurs quickly. Otherwise one would have found more examples.

A good many plasma cells could be found degenerated, the cytoplasm being either granular or unstained, and with the definite chromatin marking blurred.

Pigment granules were found all through the iris, and one noticed the same peculiarity seen in my first case (R. W.), that the pigment particles floated up in the mounting medium and lay close to the cover glass.

About two thirds back from the surface of the iris (Fig. 4) there was an irregular layer of pigment, and behind it was a band of broken up cells, apparently derived from the ciliary epithelium, which extended forwards into the pupil. Bleached specimens showed that the pigment was all extra-cellular. There were no traces of the columnar cells which form a striking part of normal sections.

The sphincter muscle could be traced as a pale band, but the cells were swollen and stained ill. There was of course no trace of the dilatator.

Over much of the ciliary body one could see in bleached sections both layers of the epithelium, but over the plane part there was more destruction reaching backwards to a thickened ora serrata. From this region much exudate had passed on to and around the periphery of the lens, but the cells were all broken up. The lens capsule had given way and lymphocytes and mononuclear cells could be seen inside it.

The choroid near the ciliary body contained some lymphocyte 
collections but further back was normal. The retina was in place, but showed numerous changes, probably more fundamental than the microscopic appearances suggested as the eye was blind. The larger vessels had sheaths of lymphocytes (Fig. 9), and these cells had penetrated in many places into the vitreous (Fig. 10). Elsewhere in the retina they were few. Plasma cells were numerous. They lay in a regular layer along the membrana limitans interna which seemed abnormally thick, their nuclei were all next to the membrana, nowhere had they penetrated it, and none were to be seen in the vitreous. The small vessels of the retina were all covered by a coating of plasma cells (Figs. 11, 12), and one could not see the vessel walls except in section. Most of these vessels lay parallel to the surface, but they gave off branches which one could follow by means of the plasma cells on them, and which passed deeply as far back as the back of the layer of bipolar cells. No plasma cells could be found deeper than this layer. This agrees of course with the normal blood vessel distribution. The outer layers of the retina seemed to be normal, but near the optic nerve Heidenhain's stain showed a number of the cone nuclei stained an intense black. This appeared in all sections.

In front of the optic nerve there was a collection of cells of many kinds evidently derived from the papilla, lymphocytes, plasma cells, endothelial cells, and a few giant cells with many oval nuclei staining ill. The central vessels of the nerve had lymphocyte sheaths and there were lymphocytes in the position of the lamina cribrosa.

All through the eye the separation of lymphocytes from plasma cells was noticeable, and suggestive of different origins. The plasma cell marking in nuclei, which were still elongated and which seemed to have intermediates between them and endothelial cells, further indicates an origin from the latter as found on the outside of blood vessels. The stationary character of the plasma cells is shown by their failure to pass the membrana limitans interna, and their relative fewness inside the blood vessel tubes. They are, however, the outstanding feature in the histology of the case, and are in infinitely greater numbers than either lymphocytes or endothelial cells. One gets the impression that they are the response to a toxin, but not to that of ordinary sepsis, since there was not a single leucocyte to be found anywhere outside the blood vessels, and few even in them.

One may notice that Heidenhain's stain will stain microbes black if the staining process be long continued, but no evidence of bacteria could be found anywhere.

It is interesting to note that though the retinal changes were not excessive, the eye was blind. I have seen the same result in the eye of a leper. In it the retina appeared to be quite normal, and all 
changes to be confined to the anterior segment of the eye. Possibly special methods of staining might show degeneration of the ganglion cells.

The two cases are apparently the two extremes of what we know as sympathetic disease. In one the inflammation is of the septic type; characterised by leucocytic extravasation, and some lymphocyte collections, in the other by the absence of leucocytes, but with some lymphatic collections and with much plasma cell formation. The common type shows mainly lymphocyte nodules.

One would hope that the third case is unique. To find destructive sympathetic disease following a successful operation for cataract, where the only evidence of inflammation was the presence of a few precipitates on Descemet's membrane which were visible for a few weeks at most is fortunately unusual.

It is, however, evident from the case E. B., where a possibly dangerous eye was removed, that one does not do all that is necessary unless one makes a careful slit-lamp examination of the remaining eye before the case leaves hospital, and again afterwards till safety is assured. The same would hold good for any postoperative evidence, however slight, if iridocyclitis is present, though in a case like my last it is difficult to see what one could have done to prevent trouble, in the face of the fact that the exciting eye was and is free from disease.

\title{
AN UNUSUAL CASE OF NEURO-EPITHELIOMA OF THE RETINA
}

BY

\author{
D. G. Patwardhan, D.O.(Oxon.), D.O.M.S.(Lond.), \\ M.B., B.S.(Bomb.) \\ OPHTHALMOLOGIST, B.J. MEDICAL SCHOOL \\ POONA
}

THE patient, a boy aged 6 years, was brought to Poona, Sassoon Hospital, and was admitted for treatment on June 25, 1929.

State on admission. - The patient had a tumour of the left eyeball of the size of a coconut and he complained of extreme pain in that region. He was not emaciated and the state of his health appeared to be fairly normal.

History of the case.-About six months previously the patient had an injury to the left eyeball. The eyeball was perforated and there was a good deal of haemorrhage. There was no help available from a doctor and hence he was treated by homely 